East African Medical Journal Vol. 86 No. 1 January 2009

KNOWLEDGE, ATTITUDES AND SEXUAL PRACTICES OF UNIVERSITY STUDENTS FOR ADVANCING PEER HIV EDUCATION

D. M. Othero, PhD, P. Aduma, PhD, Maseno University, School of Public Health and Community Development, Private Bag, Maseno, Kenya and C. O. Opil, BA, (Sociol.) I CHOOSE LIFE- Africa, Maseno Chapter, Maseno, Kenya

Request for reprints to: Dr. D. M. Othero, School of Public Health and Community Development, Maseno University, Private Bag, Maseno, Kenya

\title{
KNOWLEDGE, ATTITUDES AND SEXUAL PRACTICES OF UNIVERSITY STUDENTS FOR ADVANCING PEER HIV EDUCATION
}

\author{
D. M. OTHERO, P. ADUMA and C. O. OPIL
}

\begin{abstract}
Objective: To determine the current HIV/AIDS Knowledge, Attitudes and Sexual Practices (KASP) indicators among university students that would facilitate development and implementation of a peer education programme and the subsequent monitoring and evaluation of other HIV/AIDS activities.

Design: An institutional based cross-sectional study.

Setting: Maseno University, Kenya.

Subjects: Five hundred students composed of $60 \%$ males and $40 \%$ females as dictated by the university's male to female ratio.

Main outcome measures: Levels of HIV and AIDS awareness, knowledge and attitudes and the current related behavioural trends and tendencies, among the students at the University.

Results: Of the five hundred respondents included in the study, $68.5 \%$ of them reported having ever had sexual intercourse, with males being the majority at $78.2 \%$, while the females were $54.7 \%$. A large majority $(77 \%)$ of females were in current sexual relationships compared to $66.7 \%$ of males. A significant proportion $(54.8 \%)$ of first year students reported having had their first sexual intercourse at the university. Sexual activity was seen to increase from 56.9 to $71.2 \%$ among the first year students when they got to second year of study at the university. Peer pressure emerged as an important factor in students' sexual behaviour $(\mathrm{P}=\mathbf{0 . 0 0 1})$. Of the students, $32 \%$ reported having undergone HIV tests, $70.8 \%$ were willing to go for a test while $74.3 \%$ perceived they had a chance of being infected with the virus based on their previous risky sexual experiences. A significant $77.7 \%$ of the respondents affirmed having ever used condoms but only $15.8 \%$ reported consistent use.

Conclusion: High proportions of students are sexually active with peaks in first and second years of study. This is coupled with an equal inconsistent use of condoms. Peer influence emerged as an important feature in accelerating risky sexual behaviour hence the need for advancing peer education programmes in universities.
\end{abstract}

\section{INTRODUCTION}

Young people aged 15 to 24 years account for more than half of the new HIV infections worldwide each year (1). Young women are at considerably higher risk of HIV infection. In some African communities, young women aged 15 to 19 years have HIV rates six times higher than young men of the same age. Recent population-based studies suggest that there are on average 36 young women living with HIV for every ten young men. Poverty, vulnerability to sexual exploitation and coercion, and relationships with older, more sexually experienced men put girls at risk. Numbering 1.7 billion, today's youths are the largest generation ever to enter the transition to adulthood (2).

Comprising $30 \%$ of the population in the developing world, young people present a set of urgent economic, social, and political challenges that are crucial to long-term progress and stability. Youths represent a window of opportunity for reversing HIV rates, especially when effective prevention programmes reach them before they engage in risky sexual behaviour. The values, attitudes, and skills acquired by this generation of young men and women and the choices they make influence the course of current events and shape their future world in fundamental ways (1). 
In many countries hardest hit by HIV / AIDS, sexual activity begins early before marriage. Studies show that, on average, slightly more than $40 \%$ of women in sub-Saharan Africa have had premarital sex before age 20; among young men, sex before marriage is even more common. Delaying sexual debut by even a year can have a significant impact on adolescents' health and well-being and on the progress of the HIV/AIDS epidemic. Skills-based HIV education is therefore important in providing young people with a basicunderstanding of HIV, help them personalise risks, and develop the self-esteem, communication, and decision making skills they need to make positive life choices (3).

A definite advantage of using peer educators is the involvement of the population targeted by the intervention. This is a positive element of participatory and community based HIV / AIDS programmes where the context of quality relationships makes it easier to foster behaviour change and indeed chances of success are very high (4). An excerpt from a study of peer education of youth in Ghana for prevention of HIV / AIDS and STIs through behaviour change maintains that peer educators are highly motivated and enthusiastic and they have a good relationship with their peers, which enhances the peer education process (5). However, given that the challenges encountered in scale-up of HIV / AIDS programmes produce strain on maintaining quality, this effect in programmesinvolving peer educators is exacerbated due to their immaturity, inexperience, and being part of the high-risk group targeted and hence prone to relapse; peers may need more supervision than adults, which could affect programme quality (6).

Nonetheless, "only through community volunteerism can projects of sufficient number, scope, coverage and value for resources and effort be achieved" (7) and hence the power of peer education programmes.

\section{MATERIALS AND METHODS}

This was an institutional based cross-sectional study that adopted both qualitative and quantitative approaches to data collection, analysis and presentation. The study population comprised of male and female undergraduate students of Maseno University, one of the seven public universities in Kenya. The university had an undergraduate student population of 3929 at the time of the study. The distribution by gender was 60 to $40 \%$ (male and female). The distribution by year of study of the respondents was as follows; 1105 ( $1^{\text {st }}$ years $)=28.1$ $\%, 926\left(2^{\text {nd }}\right.$ years $)=23.6 \%, 1079\left(3^{\text {rd }}\right.$ years -2002$)=$ $27.5 \%$ and $819\left(3^{\text {rd }}\right.$ years-2001 $)=20.8 \%$. This numbers represented the student population during the period between January and April 2005.
Stratified random sampling was used to determine the study respondents. A sample size of 500 university students was used, the stratification being their years of study. From the sample of each year of study, there was a 6:4 ratio distribution of male and female students respectively; again this was based on the actual gender population distribution. Table 1 shows the sample sizes by year of study and gender.

Data collection was preceded by a three-day training of 20 enumerators and five supervisors and pre-testing of the study tools. Quantitative data were collected using a semi-structured questionnaire administered to the sampled respondents over a period of five days. The enumerators were assigned pre-determined halls of residence along gender lines. Data were collected from $5.00 \mathrm{pm}-9.00 \mathrm{pm}$ to avoid interfering with the academic activities. Qualitative data were collected through Focus Group Discussions (FGDs) with male and female students randomly sampled from first to fourth year. The FGD guide was developed based on gaps identified from the quantitative data. Quantitative data were analysed using SPSS and generated frequencies and cross tabulations. Qualitative data were analysed manually by description, summarisation and categorisation paying attention to the study objectives and themes explored. Ethically, the respondents were assured of confidentiality and informed consent was got before participating in the quantitative and qualitative components of the study. Respondents' names were not recorded on the questionnaires.

\section{RESULTS}

Students' sexual behaviour: Respondents were asked whether they had ever had sex; had sex in the last 12 months and whether they had sexual partners at the time of the study. A significant proportion (69.0\%) reported to be sexually active, (Figure 1). More male students $(78.2 \%)$ were sexually active than the female students $(54.7 \%)$.

Table 1

Sample size distribution by year of study and gender

\begin{tabular}{|c|c|c|c|c|}
\hline \multirow{2}{*}{$\begin{array}{l}\text { Years of } \\
\text { study }\end{array}$} & \multicolumn{2}{|c|}{ Gender } & \multicolumn{2}{|c|}{ Sample size $(\%)$} \\
\hline & Male & Female & No. & $(\mathrm{n}=500)$ \\
\hline $1^{\text {st }}$ & 84 & 56 & 140 & 28 \\
\hline $2^{\text {nd }}$ & 72 & 48 & 120 & 24 \\
\hline $3^{\text {rd }}$ & 81 & 54 & 135 & 27 \\
\hline \multirow[t]{2}{*}{$4^{\text {th }}$} & 63 & 42 & 105 & 21 \\
\hline & 300 & 200 & 500 & 100 \\
\hline
\end{tabular}


Figure 1

Proportional distribution of students sexual activity

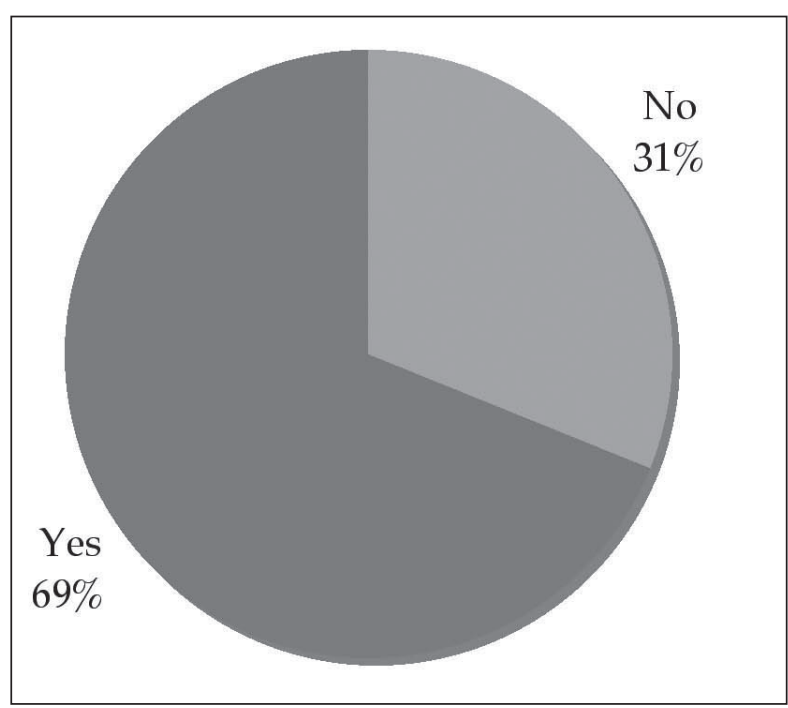

There was a significant correlation between gender and sexual activity across the years of study. Whereas most $(73.4 \%)$ of the first year male students reported to be sexually active, only $34.5 \%$ of the females reported the same but there was a greater increment of sexual activity in females than males as they progressed towards their forth year of study. The study also established that $42.4 \%$ of female students had their first sexual encounter at the university while $85.4 \%$ of males reported initiating their first sexual activity in secondary schools. More females $(77.7 \%)$ were in current sexual relationships compared to $66.7 \%$ of the males. Sexual activity among the first years greatly increased from $56.9 \%$ to $71.2 \%$ when they got to second year of study at the university as peer pressure emerged as an important factor $(\mathrm{P}=0.001)$ in influencing students' sexual behaviour. Focus Group Discussion participants who were sexually active affirmed that abstinence and virginity are "old fashioned", "impossible" and for the "weak and boring men and women".

One discussant noted: "Virginity and abstinence are impossible on campus because sexual compatibility must be tested before marriage. Abstinence is a sign of weakness and relationships should always be measured by the intensity of sexual activity involved"

Number of sexual partners in the last 12 months: On responding to the question on number of sexual partners in the last 12 months, majority (35\%) of the respondents reported to have a single sexual partner, $17 \%$ had more than two partners while another $17 \%$ reported to have had sexual activities before but had no sexual partner in the last 12 months. A significant $31 \%$ gave no response to this question (Figure 2 ).
Figure 2

Percent distribution of respondents by sexual partners

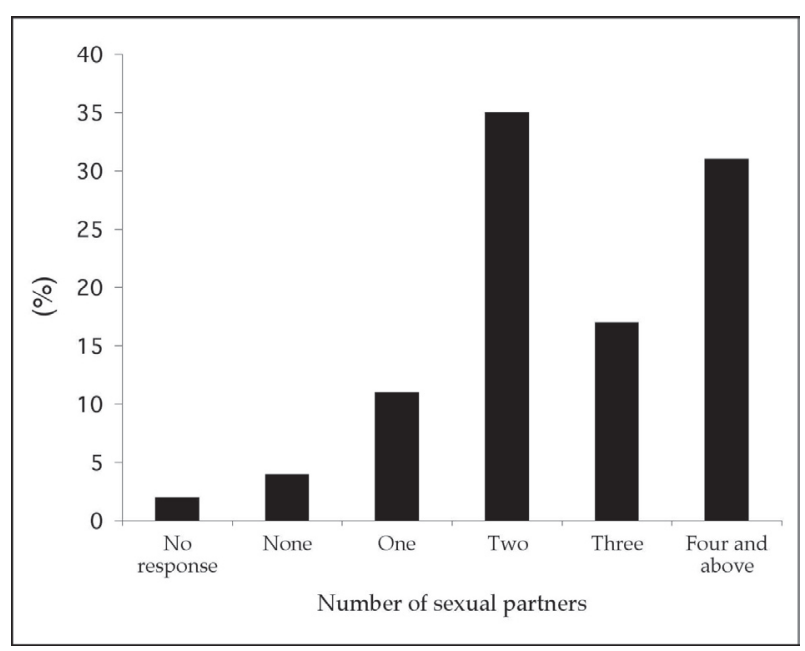

On probing for the non-responses in the FGDs, discussants expressed that the question on number of sexual partners was too personal and intimidating. "One would hardly want to share such information with anyone else".

The role of peer influence on students' sexual behaviour: When asked to discuss the role of peer influence on sexual practices, the respondents reported the following as some of the ways it influences sexual behaviour:

(i) Majority of male students share their sexual experiences with their friends.

(ii) Female students discuss boyfriends in groups and thus influence each other.

(iii) Males taut each other over sexual heroism and compete as to who would have the highest number of girls attached to them.

(iv) Male friends bet over having sex with certain identified girls and in the process influence each other's decisions.

(v) Fashion plays a role in peer influence. Male students are easily triggered into sexual behaviour by the dressing code of the female students.

(vi) Pornographic material supplied by friends and watched during parties act as catalysts towards sexual activity among students.

The role of alcohol in students' behaviour: Discussants in focus groups observed that majority of the female students engaged in sexual activity under theinfluence of alcohol. It was confirmed that sexual activity was particularly high during parties and most students attended parties seeking sexual fulfillment. Most of the female respondents asserted that alcohol made them forget the bitter fact that they were to have sex with total strangers, while males said that alcohol made them brave and bold to ask for sex. 
Perceptions on HIV and AIDS

HIV testing: A relatively smaller (32\%) proportion of the respondents were aware of their HIV status having been tested in different places. Of the $32 \%$ tested, $9.2 \%$ reported having undergone the test in a hospital, $19.7 \%$ in a VCT centre, $2.4 \%$ in private clinics while $6 \%$ used self-test kits. Fewer females had been tested with only $12.1 \%$ of the first year female respondents having undergone HIV tests. It was of interest to note that $74.4 \%$ of the respondents felt that they were at risk of contracting HIV based on their previous risky sexual practices, an aspect that instilled fear of seeking VCT services. The qualitative study indicated limited willingness of students to go for VCT, the overriding factor being fear of knowing one's status.

Condom use: The study established that majority $(77.5 \%)$ of the sexually active respondents had used condoms although only $15.8 \%$ reported using condoms consistently. A significant proportion (22.5\%) reported not using condoms at all during sexual intercourse. This represents a very substantial number of respondents with fatalistic attitudes towards condom use. When asked if they would recommend condom use to friends, respondents who never used condoms affirmed that they would not recommend to friends as they believed that condoms served no purpose in preventing spread of HIV and other STIs. Female discussants in Focus Group Discussions asserted that the decision to use a male or female condom rested on the man.

HIV and AIDS stigma and discrimination: A large proportion $(91.4 \%)$ of the respondents reported knowing someone living with HIV or having died of AIDS related conditions. The qualitative study carried strong negativesentiments by the respondentstowards positive partners. There is a lot of discrimination among the male respondents than the females as to their reactions towards a positive partner. Table 2 gives a summary of the responses.

Table 2

Reactions to all infected partner

Supposing your boyfriend/girlfriend tells you that he/she is HIV+ what would you do?

\begin{tabular}{ll} 
Female & Male \\
\hline $\begin{array}{l}\text { Discuss way forward } \\
\text { with him }\end{array}$ & Rage \\
Blame & She infected me \\
Break up & Ditch the relationship \\
I am infected too & Keep it secret \\
Console him & Visit a VCT \\
\hline
\end{tabular}

HIV/AIDS related training: At least $42 \%$ of the respondents reported havinghad training on different areas and topics related to HIV / AIDS. When broken down to specific topics, a small fraction of the male
(24\%) respondents have had training on the effects of HIV / AIDS, $13 \%$ have had treatment of AIDS and $11 \%$ on Home Based Care.

\section{Suggested areas of training:}

(i) HIV prevention and behaviour change: This would help change the negative peer influence among the respondents and also reduce the level of risk involvement of the students as a result of lack of sufficient knowledge on HIV / AIDS.

(ii) Living with PLWHAs and providing support and care to them: This would address stigma and discrimination within the university. Training on support through counselling enables the students to address the needs of the PLWHAs amidst them.

(iii) VCT uptake and importance of knowledge of HIV status: This would serve the purpose of increasing VCT uptake among the students and address the fears associated with knowledge of status and also informing the students on positive living.

\section{DISCUSSION}

The study established that more than a quarter of the students $(37.5 \%)$ initiated sexual activity at the university. While more males started sexual activity at primary and secondary school levels, more females initiated sexual activity at the post-secondary and university levels. It is evident from this study that students tend to engage in short-term relationships. The fact that some students engage in casual sex strengthens the notion that knowledge alone is not adequate to effect behaviour change. Thisstudy shows differences between male and female students in their approaches to relationships and sex. Female students are more interested in nurturing a relationship while the males are more interested in having fun. In the Focus Group Discussions, more females believed in the possibility of having a relationship without sex compared to the males. This could partly explain the higher proportions of females reporting that they are in current relationships (77.7\%) compared to males (66.7\%). A similar study at Moi University, Kenya found that while $62.7 \%$ of first year students entered university as virgins, by the end of the second year, the number reporting that they were still virgins had already dropped to $49 \%$. The same report showed that $87.7 \%$ of the female second year students had had sex within 12 months (8).

It is clear from the study results that university students become increasingly sexually active as they advance in their years of study. An important aspect to note is that by the time first year females join the university; the continuing male students are eagerly waiting for them. The new environment, the unprecedented interest from males and the freedom available to them increases their vulnerability. This partly explains the major leap in sexual activity 
between first and second year. Furthermore the need for money to survive also causes pressure on the female students to engage in sexual activities. Other studies revealed similar findings (2).

Although the university makes an effort through the orientation process to sensitise first years about university life, the role of peer influence cannot be downplayed. It is also important to note that by 4th year the students become more stable in their relationships, maybe due to the fact that they have matured through the system. It is probable that they can be used to reach out to the new comers through sharing their experiences that are relevant to the lives of their fellow students. There are contradictions between the desired sexual behaviour and practice among the students. Although a higher proportion of them would like to postpone sex until after marriage (76.0\% females and $56.8 \%$ males), an equally high proportion is sexually active (68.5\%). In addition, although a higher proportion feels that a relationship without sex is desirable, many are sexually active. These contradictions have been alluded to in similar studies (9). The quantitative results show a significant relationshipbetween peer influenceand sexual activity $(\mathrm{P}=0.001)$. Considering the results on peer influence as a predisposing factor to risky sexual behaviours, FGD participants observed that peer influence results in the desire to indulge in sexual relationships; belong to sexual orgies and try out new sexual partners. The practice of young women befriending older men who are able to meet their material needs was also cited as a risk factor associated with peer influence. Such relationships expose female students to HIV risks because the older people will have had a longer exposure to HIV (10) and also such men would be more likely to be engaged in multiple sexual partnerships.

Alcohol consumption was also found to influence sexual activity. The respondents felt that it contributed immensely to risk taking. They identified its impairment of decision-making, abilities as contributing to pre-marital and unprotected sex. The fact that women are used or abused while drunk cannot be ignored. It is, however, notable that reports of sexual harassment are rare on campus although there are indications that it does occur. This is not peculiar to this group. Studies conducted elsewhere show that people rarely report sexual abuse due to fear of stigma and further victimisation in their own homes and communities $(11,12)$.

There is evidence that VCT services influence behaviour change, however, only few $(28.2 \%)$ of the students have undergone HIV testing. VCT has been shown to motivate behaviour change, especially for those who are HIV negative, while for those positive it leads to positive living with the virus. Research in Kenya, Tanzania and Trinidad has demonstrated a 40 to $46 \%$ decreasein reported unprotected sexualintercourse among those who have received VCT services (13). The low levels of HIV testing at Maseno University implies that most students are missing out on the benefits of testing including reduced sexual activity, increased consistent use of condoms and a positive perception towards peopleinfected with HIV. Themain reason cited for unwillingness to test is fear of a positive result.

In conclusions, a high proportion of students are sexually active with the latter being more evident between firstand second years of study. Sexual activity is mostly influenced by peer pressure. Although the students know where to go for HIV testing and have easy access to VCT services, few have been tested due to fear of testing positive. Finally, the traditional role definitions for men and women still pervade the university as male students make most decisions on sexual activities including condom use.

We recommend that there is need for development of peer education training programmes that would address a range of issues including HIV transmission, care, prevention and support. It is notablethat although students recognise the importance of condom use, a larger majority are still not using them consistently. The study recommends an intensive condom campaign within the university in order to increase accessibility and change attitudes towards condom use.

\section{REFERENCES}

1. UNAIDS report on the global AIDS epidemic, 2006.

2. Amuyunzu-Nyamongo, M. and Kiragu, K. Gender roles and sexual behaviour in Africa. AIDS in Africa: Scenarios for the Future, UNAIDS. 2003.

3. Mashegoane, S. Sexual sensation seeking and risky sexual behaviour among South African University students, Social behaviour and Personality. 2002.

4. DeJong. Making an impact in HIV/AIDS, ITDG. 2003.

5. UNICEF Ghana, Evaluation of HIV/AIDS prevention through peer education, counseling, health care, training and urban refuges in Ghana, Evaluation and Programme Planning 25; 2002.

6. ETR Associates, Characteristics of Effective Peer Education Programs Article, 2005, http ://www.etr. orglrccapp/theories/peereducation/characteristics.htm

7. Kanyama, Kanyama Project Report. Lusaka, Zambia, 1998.

8. IChoose Life, Moi University Baseline Survey Report, 2005.

9. Bandawe, C.R. and Foster, D. AIDS-related beliefs, altitudes and intentions among Malawian students in three secondary schools. AIDS Care. 1996; 8: 223-232.

10. UNAIDS. Report on the global AIDS epidemic. 4th Global Report. UNAIDS, Geneva. 2004.

11. Wambua, L., Amuyunzu-Nyamongo, M., Omurwa, T., et al. Violence against adolescents: A Silent ill in rural Eastern Africa. East Afr. Med. J. 2000; 77: (Supplement): S2-S6.

12. FIDA 2002. Staking our claim. The 2002 FIDA Kenya Annual Report on the Legal Status of Women. Federation of Women Lawyers, Kenya.

13. Liverpool VCT and Care Kenya. VCT Guidelines. Nairobi, Kenya. 2003. 